Financial Risk and Management Reviews

2021 Vol. 7, No. 1, pp. 26-35.

$\operatorname{ISSN}(e): 2411-6408$

$\operatorname{ISSN}(p): 2412-3404$

DOI: 10.18488/journal.89.2021.71.26.35

(C) 2021 Conscientia Beam. All Rights Reserved.

check for
updates

\title{
A BLOCKCHAIN RESEARCH REVIEW
}

(D) Mohammad Tariq
Hasan $^{1+}$
(iD Mahadi Hasan
Miraz $^{2}$
(iD Farhana Rahman
Sumi $^{3}$
(D) Shumi Sarkar

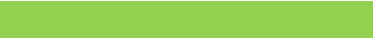

Article History

Received: 8 June 2021

Revised: 12 July 2021

Accepted: 16 August 2021

Published: 6 September 2021

\section{Keywords}

Blockchain

Meta-analysis

Cryptocurrency

Bitcoin

Decentralize

Technology.

JEL Classification:

M1; G1; G15.

\author{
'Assistant Professor, School of Business and Economics, United International \\ University (UIU), Bangladesh. \\ 'Email: tariq2060@gmail.com Tel: +8801755577344 \\ ${ }^{2}$ Assistant Principle, Inasis YAB and Muamalat, Universiti Utara Malaysia \\ (UUM), Malaysia. \\ 'Email:mahadimiraz1@gmail.com Tel:+60147958289 \\ ${ }^{s, 4}$ Assistant Professor, Department of Business Studies, University of \\ Information Technology and Sciences (UITS), Bangladesh. \\ ${ }^{3}$ Email:farhana.abrar@gmail.com Tel: +8801947741903 \\ ${ }^{ \pm}$Email:sarkar.shumi@gmail.com Tel: +8801611080468
}

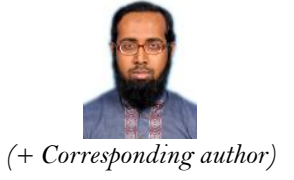

(+ Corresponding author)

\begin{abstract}
Blockchain technology was first introduced as Bitcoin's underlying technology which is one type of distributed ledger that consists of replicated, shared, and synchronized data over the Internet. This study extends prior studies on blockchain. A fundamental framework for a blockchain research classification was proposed by analyzing 230 articles related to the study of blockchain published in Asia and around the world from 2016 to 2020. The study applies a comprehensive meta-analysis based on findings, literature sources, research objectives, research methods, and context. The objective of the study is to summarize the current blockchain research, its constraints, and future trends. Meta-analysis is characterized by the process of theory construction. It is a powerful tool to analyze the literature in a descriptive form which will guide for further study. Research shows that the study at home is more decentralized, non-systematic, and has failed to gain a certain research depth-Moreover, it lacks quantitative analysis. Future research will focus on digital currency, Internet financing, and the risk of blockchain technology research.
\end{abstract}

Contribution/Originality: This study contributes to the existing literature by examining the previous studies in the period of 2016-20 which help us to comprehend the scope of study on blockchain.

\section{INTRODUCTION}

The blockchain was first published in Satoshi Nakamoto's 2008 article "Bitcoin: A Peer-to-Peer Electronic Cash System” (Nakamoto, 2008). He proposes an electronic currency: Bitcoin, based on the P2P (Miraz, Hasan, \& Sharif, 2019a; Miraz, Hasan, \& Sharif, 2020a) system design's decentralized structure to solve a trust problem (Luther, 2016). Further study of the blockchain diversifies its application. In January 2015, the "Bretton Woods System 2015 White Paper" was published at the Bitcoin conference in Miami, USA (Cao, Cao, Wang, \& Lu, 2017). The three phases were proposed for blockchain development: the Blockchain 1.0 phase, an encrypted digital currency (Miraz, Hasan, \& Sharif, 2019b; Miraz, Hasan, Sumi, Sarkar, \& Majumder, 2020b). It is reflected mainly in the Bitcoin application: blockchain 2.0 stage, smart deal (Gatteschi, Lamberti, Demartini, Pranteda, \& Santamaría, 2018). Blockchain is used on financial or economic markets (Miraz et al., 2019a; Miraz et al., 2020a) and extends into inventories, bonds, futures, loans, mortgages, ownership rights, IPP, and other agreements (Chu \& Gao, 2019). 
Blockchain 3.0 phase, a very innovative step of the application (Maesa \& Mori, 2020). It is widely used in certain public services worldwide (Hou, 2017). All walks of life are very interested in blockchain development and think its prospects are excellent (Cao et al., 2017). The academic community believes that blockchain does involve the financial industry and subverts the entire society's operation (Cao et al., 2017). Regulators are more concerned that blockchain will change and have an impact on economy (Shanaev, Sharma, Ghimire, \& Shuraeva, 2020).

Moreover, the blockchain redefines human life and has a high value for research (Lu, 2019). The British government published an essential report on blockchain technology in December 2020 (Ali, Ally, \& Dwivedi, 2020). In the story called "Distributed Book Technology: Beyond the blockchain," the federal government in Great Britain explores the distributed account technology similar to blockchain technology and examines blockchain's potential in the traditional financial sector $(\mathrm{Lu}, 2019)$. In addition, few researchers also analyze the potential of blockchain (Miraz et al., 2020a; Miraz et al., 2020b; Miraz, Hasan, Sumi, Sarkar, \& Majumder, 2020c). The People's Bank of Asia set up a digital money technical team as early as 2014 and held a unique digital currency seminar in December 2020. During this seminar, they examined how blockchain technology can produce virtual currency to improve financial activities' efficiency, convenience, and transparency (Böhme, Christin, Edelman, \& Moore, 2015). And at the beginning of 2020, a billion US dollars were invested in the capital market to accelerate chain development (Chishti \& Barberis, 2016). This trend shows that the paper synthesizes blockchain classifications for domestic and academic papers globally (Alzahrani \& Daim, 2019; Aste, 2019; Miraz \& Ali, 2018; Miraz et al., 2019a; Miraz et al., 2019b; Nawang \& Azmi, 2020; Pandya, Mittapalli, Gulla, \& Landau, 2019; Sarwar, Nisar, \& Khan, 2019; Schaupp \& Festa, 2018; Șcheau, Crăciunescu, Brici, \& Achim, 2020; Sovbetov, 2018; Xiong \& Tang, 2020; Yang, 2016; Zulhuda \& Sayuti, 2017), then proposes a blockchain classification framework and describes blockchain characteristics (Lu, 2018). This paper's importance is that, by summarizing the blockchain study, it helps us to comprehend the present research situation and clarify the work that needs to be further improved to promote blockchain research in Asia (Abou Maroun, Daniel, Zowghi, \& Talaei-Khoei, 2018; Al-Amin, Sharkar, Kaiser, \& Biswas, 2021; Maesa \& Mori, 2020; Miraz \& Ali, 2018; Miraz et al., 2019b; Miraz 2020; Miraz et al., 2020d; Perera, Nanayakkara, Rodrigo, Senaratne, \& Weinand, 2020; Yang, 2016).

\section{THE BLOCKCHAIN CONCEPTS AND FEATURES}

The blockchain technique is superior to centralized data storage because it is decentralized (Zhang \& Chen, 2019). Blockchain does provide an element of opportunity for economic and political change (Malherbe, Montalban, Bédu, \& Granier, 2019). Both the nodes checked the details of the block together (Lu, Huang, Azimi, \& Guo, 2019). The features (Nathan, Govindarajan, Saraf, Sethi, \& Jayachandran, 2019) of the blockchain are:

1. The system does not rely on centralized administration or hardware organizations (Latif, Idrees, Ahmad, Zheng, \& Zou, 2021; Lee, Azamfar, \& Singh, 2019; Li et al., 202 1; Lin, Shen, Zhang, \& Chai, 2018).

2. Taking away faith. Data sharing is not required among the device nodes. Therefore, such a node cannot deceive all other nodes.

3. Time management. Each node in a cluster secures the database.

4. Impurities. Editing a single node does not affect all nodes in the network, and those edits cannot be used to change the information and data stored.

5. Tracing. The block includes information that can be correlated and traceable back to the front of the blocks per data.

6. Anonymity Privacy. The confidence and privacy aspects can be lost when the details about the interaction between the nodes is publicly revealed. 


\section{RESEARCH AND ANALYSIS OF LITERATURES}

In order to examine the current literature on the blockchain, we have used "blockchain" as a keyword in google scholar, academia, emailed search engine, Elsevier search engine, etc. Finally, 230 items of literature have been selected for the study based on the following criteria:

1. The selected article from January 2016 to December 2020.

2. Literature related to a blockchain.

3. Focused on published articles.

\subsection{Analysis of Literature Sources}

Our current journal classification is based on society's existing library classification system. As for the social sciences in Asia, there are as many as 230 journals that will be sorted-according to the Scientific Citation Database, organized into two groups. Total Social Science publications include finance, social science, business administration, technology, and economics. It is feasible that publications will cross several categories. Table 1 shows that there are many aspects of the research that are focused on blockchain technologies. There is a positive trend in academic research on blockchain technology, fascinating more scholars to investigate other areas of knowledge.

Table-1. Literature sources.

\begin{tabular}{l|c|c}
\hline Journal Classification & Classification Subtotal & Proportion \\
\hline Economics & 123 & $53.4 \%$ \\
\hline Management & 37 & $16 \%$ \\
\hline Technology & 54 & $23.4 \%$ \\
\hline Comprehensive social science journals & 7 & $3 \%$ \\
\hline Comprehensive university journals & 9 & $4 \%$ \\
\hline Total & 230 & $100 \%$ \\
\hline
\end{tabular}

\subsection{Analysis of Literature Research Subjects}

The 230 literature chosen would be broken into nine sections. The sections are finance, Fintech, ICT, accounting, credit, big data, Internet energy, the current status, threats, and others. Banking and finance is categorized into seven sectors as "digital currencies", "payment", "bills", "banks", "internet banking", "supply chains" and "big financial market". The figures are illustrated in Table 2.

Table-2. Analysis and types of manuscripts.

\begin{tabular}{l|l|c|c|c}
\hline No. & Research Subjects & Qualitative & Quantitative & Percentage \\
\hline 1 & Finance & 39 & 17 & $24.35 \%$ \\
\hline 2 & Fintech & 29 & 14 & $18.70 \%$ \\
\hline 3 & ICT & 20 & 14 & $14.79 \%$ \\
\hline 4 & Accounting & 9 & 15 & $10.44 \%$ \\
\hline 5 & Credit & 8 & 9 & $7.40 \%$ \\
\hline 6 & Big Data & 8 & 6 & $4.80 \%$ \\
\hline 7 & Energy Internet & 8 & 5 & $5.66 \%$ \\
\hline 8 & The status quo, future and risks & 5 & 11 & $8.27 \%$ \\
\hline 9 & Others & 131 & 8 & $5.46 \%$ \\
\hline & Total & & 99 & $100 \%$ \\
\hline
\end{tabular}

Blockchain has the most studies in finance, with about $68(39+29)$ publications by the end of year 2020. Seven sub-topics describe the topic: 


\subsubsection{Finance}

Fifty-six articles consider blockchain the underlying protocol, comprising $24.35 \%$ of all the papers. Few researchers provided the three basic concept assumptions for digital currencies; the Central Bank Accounts Model, the retention of the current financial system, and commercial banks issue the common currency (Rugeviciute \& Mehrpouya, 2019; Shanaev et al., 2020; Sulaiman \& Rahim, 2019). Blockchain technology is a technological breakthrough for addressing the issue of trust. Blockchain financial technologies will minimize settlement processes and costs of businesses. Through this, banks will have access to all rewards and threats from the distributed blockchain book (Wong, Tan, Lee, Ooi, \& Sohal, 2020). It has a significant impact on financial intermediation because banks used these new technologies. It affects the economy, money, central banking, economic structure, and settlement of payments (Asaduzzaman, Hasib, \& Hafiz, 2020; Aste, Tasca, \& Di Matteo, 2017; Ayedh, Echchabi, Battour, \& Omar, 2020). Peer-to-peer transfers, authentication, exact property, and intelligent administration are the platform's main components. Blockchain technology is an alternative to Internet payment networks (Abou Maroun et al., 2018; Al-Amin et al., 2021; Ali, Ali, Alsaawy, Khalid, \& Musa, 2019; Ali et al., 2020; Miraz et al., 2020e). It has a significant role in credit decision-making. This research shows that the link block modified the new financial credit system entirely and reduced financial risk and fraud risk. Another researcher studied the impact of blockchain on smart contracts and for small enterprise credit. Supply chain financing services are mainly provided to small-sized enterprises (Kim \& Laskowski, 2018; Ku-Mahamud, Omar, Bakar, \& Muraina, 2019; Miraz 2020; Wong et al., 2020). Also, it will provide a variety of financing products to the investors that small and mediumsized businesses need. The banker would not have the opportunity to bring financial resources because there is no core credit security for businesses (Bashir, 2018; Beck, Stenum Czepluch, Lollike, \& Malone, 2016; Berg, Novak, Potts, \& Thomas, 2018; Biswas \& Gupta, 2019). Now, blockchain technology lets information input into the data base have the guarantee of time-stamp and unalterable nature. Also, chain block articles have analyzed the impact of chain block on a financial domain (Bronder, 2018; Cao et al., 2017; Carson, Romanelli, Walsh, \& Zhumaev, 2018). First, blockchain was introduced to economic infrastructures. It was then generalized to the settlement processes of shares and cash systems, the central depository of stocks, and the lending institutions.

\subsubsection{Fintech}

Blockchain is mainly used in the Fintech research field (Fosso Wamba, Kala Kamdjoug, Epie Bawack, \& Keogh, 2020; Miraz \& Ali, 2018). It took the most research attention for research (Rugeviciute \& Mehrpouya, 2019; Sulaiman \& Rahim, 2019). From the Fintech ground, the researcher collected forty-three articles, and the ratio was $18.70 \%$.

\subsubsection{ICT}

Blockchain opened a new paradigm in the ICT sector (Ku-Mahamud et al., 2019; Miraz \& Habib, 2016; Miraz et al., 2019a; Miraz 2020; Miraz et al., 2020a; Miraz et al., 2020b; Miraz, Mohd Sharif, Hassan, \& Hasan, 2020f; Morkunas, Paschen, \& Boon, 2019; Wong et al., 2020). In the field of ICT, the research analyzed thirty-four articles with $14.79 \%$.

\subsubsection{Accounting}

Almost all of the literature in Asia deals with accountancy. Another academic explained that the blockchain would help to improve audit performance and lower the costs associated with auditing. Besides, individual businesses have started designing self-audit programs to liberate manual accounting work and bring about a fundamental shift in the corporate model. Some have simultaneously started developing auditing software. 


\subsubsection{Credit}

There are $7.4 \%$ of total study engaged in credit issues. Someone else called attention to the researcher's insistence that credit is vital in allocating economic and social capital allocation. It is difficult to ascertain whether large amounts of knowledge may be accurate or not blockchain lowers global borrowing costs, thus providing a credit infrastructure. Another researcher suggested using digital credit to bypass behaviors that make transactions impossible to reverse.

\subsubsection{Big Data}

Big data documents $4.8 \%$ of the literary study. Because of the Big Data, Far predicted that everyone would be able to take responsibility for their own data while gaining data access to reduced prices.

\subsubsection{Energy Internet}

Artificial intelligence accounts for $5.66 \%$ of Internet blockchain. In three words: The energy internet consists of three parts: power generation, delivery, and storage. This researcher points out that electricity, money, and power transmission, and capital are a better fit for blockchain technology's distributed book structure. Nonetheless, some issues persist, such as inefficiency and storage redundancy.

\subsubsection{The Status Quo, Future, and Risks}

Blockchain architecture literature, upcoming issues, and vulnerabilities represent $8.27 \%$ of the risk landscape. The researcher discusses the financial services applications, public institutions, the media, healthcare, elections, domain names, and many other fields and draws attention to the significant consequences of blockchain for privacy and alternative business models.

\subsubsection{Other}

This paper includes $5.46 \%$ literary works and canons and cannot be put into either of the above groups. He also addressed three possible military use applications for blockchain technology: intelligence operations, handling arms life cycles, and logistics. They have also summarized the challenges posed in the area of military-specific blockchain technology: To incentivize users to contribute to a community, another researcher proposed using the Cat Claw Coins to create a blockchain ecosystem to teach the users.

\subsection{Analysis of Literature Research Methods}

Several different testing methods exist, the majority of which come from quantitative and qualitative perspectives, including classification, study and literature interpretation (Saunders, Lewis, \& Thornhill, 2003; Saunders, Lewis, \& Thornhill, 2009; Scheurich, 1997). The methods and techniques used in quantitative research include methods and techniques for measuring social phenomena, the intensity of social relationships, and shifts in the amount (Sekaran \& Bougie, 2016; Taherdoost, 2016; Urbach \& Ahlemann, 2010). The theory is confirmed by a combination of statistical investigation, expert analysis, reliable statistics, and experimental methods (Sekaran \& Bougie, 2016; Taherdoost, 2016; Urbach \& Ahlemann, 2010; Weijters \& Baumgartner, 2012; Wong et al., 2020; Yusof et al., 2018; Zikmund, Babin, Carr, \& Griffin, 1991). Figure 1 described the scenario of previous literature on blockchain where $57 \%$ study used qualitative method and rest $43 \%$ used quantitative method. The primary methodology of qualitative forecasting is done by forecasters' experience and on the assessment of events based on their viewpoints and trajectories. The procedure is more useful for those who don't have complete data. 


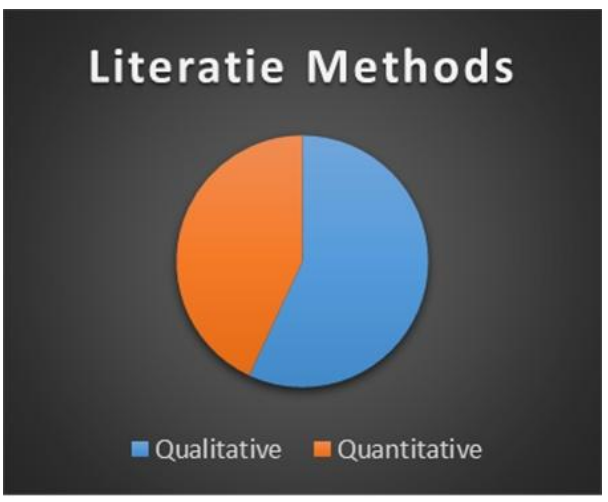

Figure-1. Literature methods.

The qualitative research's primary means of gauging findings from Table 2 reveals that it can be considerably better than the quantitative approaches used in Table 2 (100\%). People concentrate on the qualitative aspects of study due to developing the blockchain in Asia, inhibiting the latter's growth. We advocate the use of blockchain technologies to advance to the quantitative findings also, as soon as possible in this case.

\subsection{Research Limitation}

Since Asian blockchain analysis has not been systematized, finding papers on it is a challenge. In future studies, the fidelity of the reference citations should be increased. As a result, the scarcity of English-language resources, this paper only deals with a few topics. This study does not make a comparison of Asia and Western studies.

\section{CONCLUSION}

Based on our assessment of blockchain's viability, market potential, and competition, we arrive at the following conclusions: In the year of 2020 , the number of academic research papers related to the blockchain increased by an exponential factor. The media's interest in domestic scholars has increased lately because of digital money growth. Significant amounts of trade are conducted in both Bitcoins and Lehman dollars. Also, the financial periodicals found in libraries come from Economics and Technological courses. There is a distinct difference between technical papers and publications. These are mostly concerned with the concept of blockchain and magazines that are primarily about its application in business. Creative idea: Fintech seems to have an absolute edge over 187 articles (accounting for $63.4 \%$ of the search results) that cover topics like digital currencies, banks, and finances as a whole. The last category of the journal also revolves around the research's current subject. Many organizations worldwide are devoting their efforts to understanding and exploring how blockchain technology can lower their financial burden and expenses. Domestic researchers can then strive to increase their study's quantity to fulfill their role in influencing policy. Asian and foreign researchers should concentrate further in the future on the decentralized blockchain theory.

Funding: This study received no specific financial support.

Competing Interests: The authors declare that they have no competing interests.

Acknowledgement: All authors contributed equally to the conception and design of the study.

\section{REFERENCES}

Abou Maroun, E., Daniel, J., Zowghi, D., \& Talaei-Khoei, A. (2018). Blockchain in supply chain management: Australian Manufacturer case study service research and innovation (pp. 93-107). Cham: Springer.

Al-Amin, S., Sharkar, S. R., Kaiser, M. S., \& Biswas, M. (2021). Towards a blockchain-based supply chain management for e-agro business system. Paper presented at the Paper presented at the Proceedings of International Conference on Trends in Computational and Cognitive Engineering. 
Ali, J., Ali, T., Alsaawy, Y., Khalid, A. S., \& Musa, S. (2019). Blockchain-based smart-IoT trust zone measurement architecture. Paper presented at the Paper presented at the Proceedings of the International Conference on Omni-Layer Intelligent Systems.

Ali, O., Ally, M., \& Dwivedi, Y. (2020). The state of play of blockchain technology in the financial services sector: A systematic literature review. International Journal of Information Management, 54, 102199. Available at: https://doi.org/10.1016/j.ijinfomgt.2020.102199.

Alzahrani, S., \& Daim, T. U. (2019). Evaluation of the cryptocurrency adoption decision using hierarchical decision modeling (HDM). Paper presented at the Paper presented at the 2019 Portland International Conference on Management of Engineering and Technology (PICMET).

Asaduzzaman, M., Hasib, F., \& Hafiz, Z. B. (2020). Towards using blockchain technology for microcredit industry in Bangladesh. Paper presented at the Paper presented at the 2020 23rd International Conference on Computer and Information Technology (ICCIT).

Aste, T., Tasca, P., \& Di Matteo, T. (2017). Blockchain technologies: The foreseeable impact on society and industry. Computer, 50(9), 18-28. Available at: https://doi.org/10.1109/mc.2017.3571064.

Aste, T. (2019). Cryptocurrency market structure: Connecting emotions and economics. Digital Finance, 1(1-4), 5-21. Available at: https://doi.org/10.1007/s42521-019-00008-9.

Ayedh, A., Echchabi, A., Battour, M., \& Omar, M. (2020). Malaysian Muslim investors' behaviour towards the blockchain-based Bitcoin cryptocurrency market. Journal of Islamic Marketing, 12(4), 690-704. Available at: https://doi.org/10.1108/JIMA-04-2019-0081.

Bashir, I. (2018). Mastering Blockchain: Distributed ledger technology, decentralization, and smart contracts explained. USA.: Packt Publishing Ltd.

Beck, R., Stenum Czepluch, J., Lollike, N., \& Malone, S. (2016). Blockchain-the gateway to trust-free cryptographic transactions. Research Papers. 153. Retrieved from: https://aisel.aisnet.org/ecis2016_rp/153.

Berg, C., Novak, M., Potts, J., \& Thomas, S. J. (2018). From industry associations to ecosystem associations: Blockchain, interest groups and public choice. Interest Groups and Public Choice (November 16, 2018). Available at SSRN: https://ssrn.com/abstract=3285647 or http://dx.doi.org/10.2139/ssrn.3285647.

Biswas, B., \& Gupta, R. (2019). Analysis of barriers to implement blockchain in industry and service sectors. Computers $\mathcal{E}^{\circ}$ Industrial Engineering, 136, 225-241. Available at: https://doi.org/10.1016/j.cie.2019.07.005.

Böhme, R., Christin, N., Edelman, B., \& Moore, T. (2015). Bitcoin: Economics, technology, and governance. Journal of Economic Perspectives, 29(2), 213-238. Available at: https://doi.org/10.1257/jep.29.2.213.

Bronder, P. (2018). Effective disruption: How blockchain technology can transform the energy sector Sustainable Innovation and Impact (1st ed., pp. 208-2 12). London: Routledge.

Cao, S., Cao, Y., Wang, X., \& Lu, Y. (2017). A review of researches on blockchain. Paper presented at the Paper presented at the Wuhan International Conference on e-Business.

Carson, B., Romanelli, G., Walsh, P., \& Zhumaev, A. (2018). Blockchain beyond the hype: What is the strategic business value (pp. 1-13): McKinsey \& Company.

Chishti, S., \& Barberis, J. (2016). The Fintech book: The financial technology handbook for investors, entrepreneurs and visionaries: John Wiley \& Sons.

Chu, S., \& Gao, C. (2019). Intellectual property protection and creative enterprises' investment efficiency: Alleviating financing constraints or inhibiting agency problem? Asia-Pacific Journal of Accounting \& Economics, 26(6), 747-766. Available at: https://doi.org/10.1080/16081625.2019.1566010.

Fosso Wamba, S., Kala Kamdjoug, J. R., Epie Bawack, R., \& Keogh, J. G. (2020). Bitcoin, Blockchain and Fintech: A systematic review and case studies in the supply chain. Production Planning \& Control, 31(2-3), 115-142. Available at: https://doi.org/10.1080/09537287.2019.1631460. 
Gatteschi, V., Lamberti, F., Demartini, C., Pranteda, C., \& Santamaría, V. (2018). Blockchain and smart contracts for insurance: Is the technology mature enough? Future Internet, 10(2), 1-16. Available at: https://doi.org/10.3390/fi 10020020.

Hou, H. (2017). The application of blockchain technology in E-government in China. Paper presented at the Paper presented at the 2017 26th International Conference on Computer Communication and Networks (ICCCN).

Kim, H. M., \& Laskowski, M. (2018). Toward an ontology-driven blockchain design for supply-chain provenance. Intelligent Systems in Accounting, Finance and Management, 25(1), 18-27. Available at: https://doi.org/10.1002/isaf.1424.

Ku-Mahamud, K. R., Omar, M., Bakar, N. A. A., \& Muraina, I. D. (2019). Awareness, trust, and adoption of blockchain technology and cryptocurrency among blockchain communities in Malaysia. International Journal on Advance Science Engineering Information Technology, 9(4), 12 17-1222. Available at: https://doi.org/10.18517/ijaseit.9.4.6280.

Latif, S., Idrees, Z., Ahmad, J., Zheng, L., \& Zou, Z. (2021). A blockchain-based architecture for secure and trustworthy operations in the industrial Internet of Things. Journal of Industrial Information Integration, 21, 100190. Available at: https://doi.org/10.1016/j.jii.2020.100190.

Lee, J., Azamfar, M., \& Singh, J. (2019). A blockchain enabled cyber-physical system architecture for Industry 4.0 manufacturing systems. Manufacturing Letters, 20, 34-39. Available at: https://doi.org/10.1016/j.mfglet.2019.05.003.

Li, C. Z., Chen, Z., Xue, F., Kong, X. T., Xiao, B., Lai, X., \& Zhao, Y. (2021). A blockchain-and IoT-based smart product-service system for the sustainability of prefabricated housing construction. Journal of Cleaner Production, 286, 125391. Available at: https://doi.org/10.1016/j.jclepro.2020.125391.

Lin, J., Shen, Z., Zhang, A., \& Chai, Y. (2018). Blockchain and IoT based food traceability for smart agriculture. Paper presented at the Paper presented at the Proceedings of the 3rd International Conference on Crowd Science and Engineering.

Lu, Y. (2018). Blockchain and the related issues: A review of current research topics. Journal of Management Analytics, 5(4), 231255. Available at: https://doi.org/10.1080/23270012.2018.1516523.

Lu, Y. (2019). The blockchain: State-of-the-art and research challenges. Journal of Industrial Information Integration, 15, 80-90. Available at: https://doi.org/10.1016/j.jii.2019.04.002.

Lu, H., Huang, K., Azimi, M., \& Guo, L. (2019). Blockchain technology in the oil and gas industry: A review of applications, opportunities, challenges, and risks. IEEE Access, 7, 41426-41444. Available at: https://doi.org/10.1109/access.2019.2907695.

Luther, W. J. (2016). Bitcoin and the future of digital payments. The Independent Revierw, 20(3), 397-404.

Maesa, D. D. F., \& Mori, P. (2020). Blockchain 3.0 applications survey. Journal of Parallel and Distributed Computing, 138, 99-114. Available at: https://doi.org/10.1016/j.jpdc.2019.12.019.

Malherbe, L., Montalban, M., Bédu, N., \& Granier, C. (2019). Cryptocurrencies and blockchain: Opportunities and limits of a new monetary regime. International Journal of Political Economy, 48(2), 127-152. Available at: https://doi.org/10.1080/08911916.2019.1624320.

Miraz, M. H., \& Habib, M. M. (2016). ICT Adoption in small and medium enterprises: An empirical evidence of service sectors in Bangladesh Journal of Economics. Business and Management, 4(8), 481-487.

Miraz, M. H., \& Ali, M. (2018). Applications of blockchain technology beyond cryptocurrency. Annals of Emerging Technologies in Computing (AETiC), 2(1), 1-6. Available at: https://doi.org/10.33166/AETiC.2018.01.001.

Miraz, M. H., Hasan, M. G., \& Sharif, K. I. (2019a). Blockchain technology implementation in Malaysian retail market. Journal of Advanced Research in Dynamical \& Control Systems, 11(5), 991-994.

Miraz, M. H., Hasan, M. G., \& Sharif, K. I. (2019b). The numerous tactical plans affect customer and postal service relationship: The mediating role of blockchain, an empirical study in Bangladesh. Journal of Advanced Research in Dynamical and Control Systems, $11(5), 985-990$.

Miraz, M. (2020). Blockchain in automotive supply chain. International Supply Chain Technology Journal, 6(6), 1-12. Available at: https://doi.org/10.20545/isctj.v06.io6.02.

Miraz, M. H., Hasan, M. G., \& Sharif, K. I. (2020a). Factors affecting implementation of blockchain in retail market in Malaysia. International Journal of Supply Chain Management, 9(1), 385-391. 
Miraz, M. H., Hasan, M. T., Sumi, F. R., Sarkar, S., \& Majumder, M. I. (2020b). The innovation of blockchain transparency\& traceability in logistic food chain. International Journal of Mechanical and Production Engineering Research and Development (IJMPERD), 1O(3), 9155-9170.

Miraz, M. H., Hasan, M. T., Sumi, F. R., Sarkar, S., \& Majumder, M. I. (2020c). Understanding, supervision, strategy and acceptance effect into the blockchain employment in Malaysia. International Journal of Mechanical and Production Engineering Research and Development (IJMPERD), 1O(3), 8339-8360. Available at: https://doi.org/10.24247/ijmperdjun2020793.

Miraz, M. H., Hye, A. K. M., Alkurtehe, K. A. M., Habib, M. M., Ahmed, M. S., Molla, M. S., \& Hasan, M. T. (2020d). The effect of blockchain in transportation Malaysia. International Supply Chain Technology Journal, 6(1), 1-10.

Miraz, M. H., Hye, A. K. M., Wahab, M. K., Alkurtehe, K. A. M., Majumder, M. I., Habib, M. M., \& Alsabahi, M. A. (2020e). Blockchain securities to construct inclusive, digital economy globally. International Supply Chain Technology Journal, 6(1), 1-11. Available at: https://doi.org/10.20545/isctj/v06.io1.03.

Miraz, M. H., Mohd Sharif, K. I., Hassan, M. G., \& Hasan, M. T. (2020f). Trust impact on Blockchain \& Bitcoin monetary transaction. Journal of Advanced Research in Dynamical and Control Systems, 12(SP3), 155-162. Available at: https://doi.org/10.5373/jardcs/v12sp3/20201249.

Morkunas, V. J., Paschen, J., \& Boon, E. (2019). How blockchain technologies impact your business model. Business Horizons, 62(3), 295-306. Available at: https://doi.org/10.1016/j.bushor.2019.01.009.

Nakamoto, S. (2008). Re: Bitcoin P2P e-cash paper. The cryptography mailing list. Retrieved from: http://users.encs.concordia.ca/ clark/biblio/bitcoin/Nakamoto\%202008.pdf.

Nathan, S., Govindarajan, C., Saraf, A., Sethi, M., \& Jayachandran, P. (2019). Blockchain meets database: Design and implementation of a blockchain relational database. arXiv preprint arXiv:1903.01919.

Nawang, N. I., \& Azmi, I. M. A. G. (2020). Cryptocurrency: An insight into the Malaysian regulatory approach. Hamdard Islamicus, 43(2), 262-271.

Pandya, S., Mittapalli, M., Gulla, S. V. T., \& Landau, O. (2019). Cryptocurrency: Adoption efforts and security challenges in different countries. HOLISTICA - Journal of Business and Public Administration, 10(2), 167-186. Available at: https://doi.org/10.2478/hjbpa-2019-0024.

Perera, S., Nanayakkara, S., Rodrigo, M., Senaratne, S., \& Weinand, R. (2020). Blockchain technology: Is it hype or real in the construction industry? Journal of Industrial Information Integration, 17, 100125. Available at: https://doi.org/10.1016/j.jii.2020.100125.

Rugeviciute, A., \& Mehrpouya, A. (2019). Blockchain, a panacea for development accountability? A study of the barriers and enablers for Blockchain's adoption by development aid organizations. Frontiers in Blockchain, 2, 15-27. Available at: https://doi.org/10.3389/fbloc.2019.00015.

Sarwar, M. I., Nisar, K., \& Khan, A. (2019). Blockchain-from cryptocurrency to vertical industries-a deep shift. Paper presented at the 2019 IEEE International Conference on Signal Processing, Communications and Computing (ICSPCC).

Saunders, M., Lewis, P., \& Thornhill, A. (2003). Research methods forbusiness students. Essex: Prentice Hall.

Saunders, M., Lewis, P., \& Thornhill, A. (2009). Research methods for business students. London: Pearson Education.

Schaupp, L. C., \& Festa, M. (2018). Cryptocurrency adoption and the road to regulation. Paper presented at the Proceedings of the 19th Annual International Conference on Digital Government Research: Governance in the Data Age.

Șcheau, M. C., Crăciunescu, S. L., Brici, I., \& Achim, M. V. (2020). A cryptocurrency spectrum short analysis. Journal of Risk and Financial Management, 13(8), 184. Available at: https://doi.org/10.3390/jrfm 13080184.

Scheurich, J. J. (1997). Research method in the postmodern (1st ed.). London: Routledge.

Sekaran, U., \& Bougie, R. (2016). Research methods for business: A skill building approach. USA: John Wiley \& Sons.

Shanaev, S., Sharma, S., Ghimire, B., \& Shuraeva, A. (2020). Taming the blockchain beast? Regulatory implications for the cryptocurrency Market. Research in International Business and Finance, 51, 101080. Available at: https://doi.org/10.1016/j.ribaf.2019.101080. 
Sovbetov, Y. (2018). Factors influencing cryptocurrency prices: Evidence from bitcoin, ethereum, dash, litcoin, and monero. Journal of Economics and Financial Analysis, 2(2), 1-27.

Sulaiman, M. Y., \& Rahim, R. A. (2019). Blockchain and distributed ledger technology (DLT) report 2019: Malaysia IndustryGovernment Group For Higher Education (MIGHT). 1-125. Retrieved from: https://www.might.org.my/event/malaysia-blockchain-distributed-ledger-technology-outlook-2019-reportblockchain-in-government-consultative-session/.

Taherdoost, H. (2016). Sampling methods in research methodology; how to choose a sampling technique for research. International Journal of Academic Research in Management (IJARM), 5(3), 18-27.

Urbach, N., \& Ahlemann, F. (2010). Structural equation modeling in information systems research using partial least squares. Journal of Information Technology Theory and Application, 1 1(2), 5-40.

Weijters, B., \& Baumgartner, H. (2012). Misresponse to reversed and negated items in surveys: A review. Journal of Marketing Research, 49(5), 737-747. Available at: https://doi.org/10.1509/jmr.11.0368.

Wong, L.-W., Tan, G. W.-H., Lee, V.-H., Ooi, K.-B., \& Sohal, A. (2020). Unearthing the determinants of Blockchain adoption in supply chain management. International Journal of Production Research, 58(7), 2100-2123. Available at: https://doi.org/10.1080/00207543.2020.1730463.

Xiong, J., \& Tang, Y. (2020). Mobile cryptocurrency for development in Asia-moderating effects of advantage, complexity, and compatibility. Paper presented at the AMCIS 2020 Proceedings. 9.

Yang, M. (2016). Cryptocurrency in China: Light-touch regulation in demand.

Yusof, H., Munir, M. F. M. B., Zolkaply, Z., Jing, C. L., Hao, C. Y., Ying, D. S., . . Leong, T. K. (2018). Behavioral intention to adopt blockchain technology: Viewpoint of the banking institutions in Malaysia. International Journal of Advanced Scientific Research and Management, 3(10), 274-279.

Zhang, X., \& Chen, X. (2019). Data security sharing and storage based on a consortium blockchain in a vehicular ad-hoc network. IEEE Access, 7, 58241-58254. Available at: https://doi.org/10.1 109/ACCESS.2018.2890736.

Zikmund, W., Babin, B., Carr, J., \& Griffin, M. (1991). Business research methods. New Year: Harcourt Brace Jovanovich, Inc.

Zulhuda, S., \& Sayuti, A. (2017). Whither policing cryptocurrency in Malaysia? IIUM Law Journal, 25(2), 179-196. Available at: https://doi.org/10.31436/iiumlj.v25i2.342.

Views and opinions expressed in this article are the views and opinions of the author(s), Financial Risk and Management Reviews shall not be responsible or answerable for any loss, damage or liability etc. caused in relation to/arising out of the use of the content. 